\title{
Fire Extinguishing Effect of Mixed Agents of Halon 1301 and Inert Gases
}

\author{
NAOSHI SAITO, YUKO SASO and YOSHIO OGAWA \\ National Research Institute of Fire and Disaster \\ 14-1, Nakahara 3-chome, Mitaka, Tokyo 181, Japan \\ YUKIHISA OTSU and HIROAKI KIKUI \\ Halon Recycling and Banking Support Committee, Japan \\ 3-14, Sotokanda 5 chome, Chiyoda, Tokyo 101, Japan
}

\begin{abstract}
Multiplier effect of mixed agents of trifluorobromomethane (halon 1301) and inert gases on flame extinction has been investigated, for the purpose of minimizing the use of halons. The inert gases examined are argon, nitrogen and carbon dioxide. The fire-extinguishing efficiency was determined by flame-extinguishing concentrations for n-heptane measured with a cupburner. An additive-property equation was derived by thermodynamic considerations to predict the fire-extinguishing efficiency of mixed agents and used as a measure of multiplier-effect test. The mixed agents of halon 1301 and inert gases showed multiplier effect. There was the optimized mixing ratios of the most effective agents.

Flame-extinction temperatures were calculated for the n-heptane flames with the flameextinguishing concentrations of agents. The temperatures suggested that the chemical effect of halon 1301 was enhanced with decreasing the flame temperature by the addition of inert gases. The flame temperature and the concentration of halon 1301 determined strength of the multiplier effect of halon 1301 and inert gas.
\end{abstract}

KEYWORDS: fire-extinguishing effect, halon 1301, inert gas, mixed agent, multiplier effect

\section{INTRODUCTION}

On January 1, 1994, the production of the halon fire-extinguishing agents was ceased to protect the stratospheric ozone layer [1]. The halon phase-out program of the United Nation Environmental Plan has the following policy: (a) ban on new installation of halon fireextinguishing system, (b) promotion of halon recycling for existing equipment, and (c) employment of halon replacements. Today, several new agents have been developed and are used as the halon replacements, but almost all of them are not superior to halon 1301 in fire suppression efficiency $[2,3]$. Hence, there have been several tries to develop high-performance agents as halon 1301, but no high-performance agents like halons have been developed.

There have been a few studies on mixed fire-extinguishing agents to compensate the weakness of one agent by another [4] or to expect the interaction in binary halon mixtures [5]. Although none of these trials were successful, the idea of mixing fire suppressants is still a potential 
method for more effective use of the existing fire suppressants. For example, the combination of a "chemical" agent and a thermal agent has the possibility to exhibit multiplier effect, because the inert gas decreases the flame temperature and the chemical fire-extinguishing agent may be able to inhibits flame more effectively in the lower flame temperature $[6,7]$. The authors studied the influence of nitrogen solved in the recycled halon 1301 on the fire-extinguishing efficiency and reported the following experimental results [8]; (a) the flame-extinguishing concentration of halon 1301 containing 3\% of nitrogen is equal to that of pure halon 1301 with in the experimental error and (b) the mixture of $90 \%$ on nitrogen and $10 \%$ of halon 1301 extinguishes the $\mathrm{n}$-heptane cup-burner flame with about 0.8 time of the concentration predicted by the additive property of fire-extinguishing effect of multi-component agents. Then, the authors derived the additive-property equation on the efficiency for inert gas mixed agents form the simple thermodynamic consideration [9] and also reported the multiplier effect in the mixed agents between halon 1301 and either argon or carbon dioxide [10].

In the present paper, the authors give the summary of above-mentioned results on the efficiency of mixed agents and discuss the mechanism of multiplier effect of the mixed agents of halon 1301 and each inert gas through the adiabatic flame temperature calculations.

\section{REPRESENTATION FOR FIRE-EXTINGUISHING EFFICIENCY OF NON- INTERACTIVE MIXED AGENTS}

Previous study showed that multi-component inert gas agents have the flame extinction concentrations calculated by the following simple equation, which is derived based on the thermodynamic and algebraic consideration under a certain equivalence ratio of combustible mixtures [9].

$1 / C=\sum_{j=1}^{n} X_{j} / C_{j}$

Here, $C$ is the flame extinction concentration of the mixed agent, $n$ is the number of components, and $X_{j}$ and $C_{j}$ are the mole fraction and the flame extinction concentration of $j$ th component of the multi-component inert gas agents, respectively. In Eqn.1, it is assumed that (a) the inert-gas components of the mixed agent act as thermal diluents in flames and (b) do not interact with one another, (c) the flame extinction occurs below the threshold flame temperature, and (d) there is no difference in the combustion products between inhibited and non-inhibited flames. Although the equation has the same expression as Le Chatelier's Law [11] on the lower limits of flammability of the mixed fuels, it is not Le Chatelier's Law. Moreover, it has to be noticed that the flame extinction concentration, $C$, in Eqn.1 corresponds to the flameextinguishing concentration in the extinction of diffusion flame, and to the flammability limit in the extinction of premixed flame.

If each extinction effect of the components in a mixed agent is proportional to the concentration, Eqn. 1 can be applied to the efficiency of all kinds of mixed agents. Since Eqn.1 expresses formally the additive property of the flame-extinguishing efficiency for all kinds of mixed agents, it can be used as a measure to evaluate the multiplier effect of the mixed agent.

\section{EXPERIMENTAL AND FLAME TEMPERATURE CALCULATION}

\section{Cup burner apparatus and measurement of flame-extinguishing concentrations of mixed agents}

The cup burner apparatus [12] equips a cup of $30 \mathrm{~mm}$ in outer diameter and a chimney of 85 $\mathrm{mm}$ in inner diameter. The experiments were conducted under $25{ }^{\circ} \mathrm{C}$ and the atmospheric pressure, and air flow rate was regulated at 40 liters per minute by a mass flow controller. The flow rates of the two agents were controlled by the same type of mass flow controllers. The relative errors of the flow rates did not exceed 1 percent on each controlling system. The flame 
was allowed to burn for 7 minutes 40 seconds in the air stream before the addition of agent, then an inert gas was added gradually to the desirable constant flow rate for 20 seconds. After 8 minutes from the ignition, the addition of another agent was started and increased stepwise for every 10-second until the flame went out. The flame-extinguishing experiments were repeated more than three times at each measuring point. The flame-extinguishing concentrations were determined by the following equation.

$$
C=\frac{100 \times Q_{T}}{40+Q_{T}}
$$

In eqn. $2, C(\%)$ is the observed flame-extinguishing concentration, $Q_{T}(l / \mathrm{min})$ is the total flow rate of the mixed agent, and " 40 " means the air flow rate $(l / \mathrm{min})$.

\section{Materials}

Argon, nitrogen, carbon dioxide, and halon 1301 were used from the cylinders without further purification. The purity of halon 1301 and $n$-heptane were up to $99.9 \%$ and $99.5 \%$, respectively. The air was supplied by the oil free air compressor with dryer. The mixed agents of carbon dioxide and either argon or nitrogen, and the mixture of halon 1301 and an inert gas among argon, nitrogen or carbon dioxide were prepared through a mixing chamber after measuring the flow rate of each component.

\section{Adiabatic flame temperature calculation}

Assuming Burke-Schmann type flames for the cup burner flames [13], the adiabatic flame temperatures were calculated on the stoichiometric compositions between n-heptane and air containing the flame-extinguishing concentration of the mixed agents. The difference between the diffusion coefficients of air and agents was neglected. The calculations were carried out taking dissociation fully into account [14].

\section{RESULTS AND DISCUSSION}

\section{Observed and calculated flame-extinguishing concentrations of mixed agents and their ratios}

\section{Mixed agents of carbon dioxide and either argon or nitrogen}

To confirm the validity of Eqn.1 for non-interactive agent mixtures, the flame-extinguishing concentrations of the mixed agents of carbon dioxide and either argon or nitrogen were measured and calculated, varying argon or nitrogen mole fraction. FIGURE 1 shows the experimentally observed flame-extinguishing concentrations, $\mathrm{C}_{\mathrm{Obs}}$, of the mixed agents as a function of either argon or nitrogen mole fraction. In the figure, the symbols of circle and triangle indicate carbon dioxide-argon and carbon dioxide-nitrogen mixtures, respectively. In the figure, solid lines are the calculated flame-extinguishing concentration, $\mathrm{C}_{\mathrm{calc}}$, for both mixtures. The cup-burner flame-extinguishing concentrations of the pure agents used in the calculation are listed in TABLE 1 [15]. In FIGURE 2, the ratios of $\mathrm{C}_{\mathrm{Obs}}$ to $\mathrm{C}_{\text {calc }}$ of the carbon dioxide-argon mixture are plotted as a function of argon mole fraction, with the horizontal solid line indicating $\mathrm{C}_{\mathrm{obs}} / \mathrm{C}_{\mathrm{calc}}=1$. It can be easily seen that the experimental data agree well with the calculated values in the figure. The maximum differences between the $\mathrm{C}_{\mathrm{obs}} / \mathrm{C}_{\mathrm{calc}}$ and 1 are within 0.03 of experimental error of the measurements. The same relationship is obtained in the case of carbon dioxide-nitrogen mixture. Hence, the facts confirm that the assumption to derive Eqn.1 is reasonable and that the equation is a correct expression about the additive property for 
TABLE 1 Flame-extinguishing concentration measured by FRI cup burner for $n$-heptane flame [15]

\begin{tabular}{c|c}
\hline Agent & $\begin{array}{c}\text { Flame-extinguishing } \\
\text { concentration (\%) }\end{array}$ \\
\hline Halon 1301 & 3.4 \\
Argon & 43.3 \\
Nitrogen & 33.6 \\
Carbon dioxide & 22.0 \\
\hline
\end{tabular}

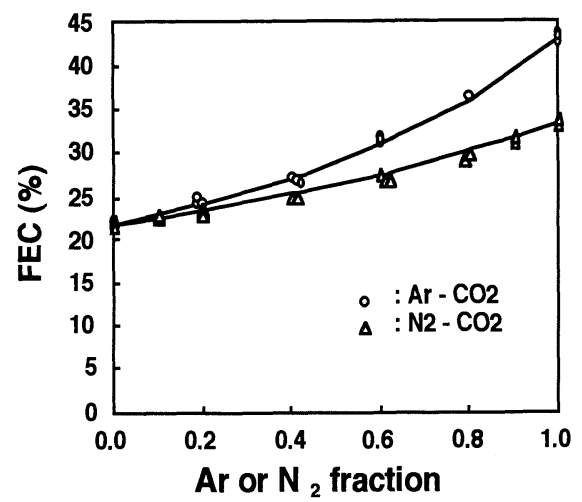

FIGURE 1 Observed (symbols) and calculated (solid lines) flame-extinguishing concentrations of $\mathrm{Ar}-\mathrm{CO} 2$ and $\mathrm{N} 2-\mathrm{CO} 2$ mixtures for n-heptane flame as functions of inert gas mole fraction

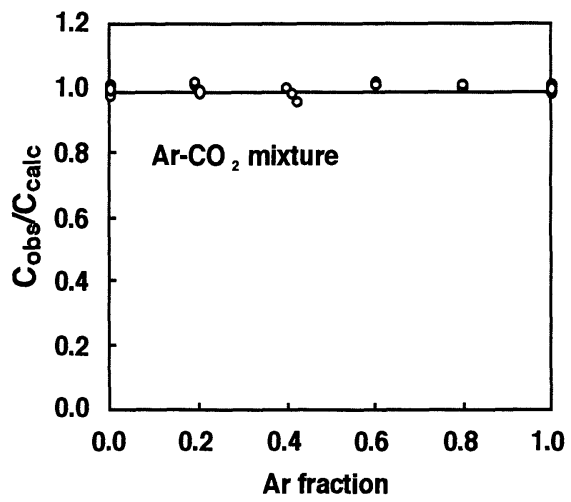

FIGURE 2 Ratios of observed to calculated extinguishing concentrations of carbon dioxide-argon mixed agent for n-heptane flame with Ar mole fraction 


\section{Mixed agents of halon 1301 and inert gas}

FIGURE 3 shows the flame-extinguishing concentrations of mixed agents of halon 1301 and argon, nitrogen or carbon dioxide, as a function of the inert gas mole fraction in the mixed agent. It is obvious that the carbon dioxide-containing agent, which has the largest specific heat, gives the lowest flame-extinguishing concentrations at larger inert gas mole fraction, that is, more effective in fire-extinction than other two mixtures. FIGURE 4 shows $\mathrm{C}_{\mathrm{Obs}}$ (circle) and $\mathrm{C}_{\text {calc }}$ (solid line) of the halon 1301-argon mixed agents as a function of argon mole fraction. There can be found the region where $\mathrm{C}_{\text {obs }}$ becomes lower than $\mathrm{C}_{\text {calc }}$ at larger mole fraction of argon. It suggests that there exists an interaction between halon 1301 and argon on the flame extinction. The same effect is found in the halon 1301 mixtures with nitrogen and carbon dioxide.

FIGURE 5 shows the variations in $\mathrm{C}_{\mathrm{obs}} / \mathrm{C}_{\text {calc }}$ with an inert gas mole fraction in the mixed agents. Clearly, all of the mixed agents containing halon 1301 have the ratios less than 1.0 over all the range of inert gas fraction. On the halon 1301-argon mixed agent, the ratio, $\mathrm{C}_{\mathrm{obs}} / \mathrm{C}_{\text {calc }}$, decreases to 0.9 at the argon mole fraction of about 0.8 , and then it approaches rapidly to the minimum value 0.77 at argon mole fraction of 0.97 . The mixed agent of halon 1301-nitrogen shows the similar trend as the argon mixed agent, but nitrogen seems to be more effective than argon. The halon 1301-carbon dioxide mixed agent is the most effective among the mixed agents examined. The ratios $\mathrm{C}_{\mathrm{obs}} / \mathrm{C}_{\text {calc }}$ of mixed agent with carbon dioxide decrease the values from 0.9 to 0.75 with increasing the carbon dioxide fraction from 0.2 to 0.95 , but the minimum value of the ratio stays in the same ratio as the other halon 1301-inert gas mixed agents. Although carbon dioxide is the most effective inert gas in the use with halon 1301 as stated above, the mixed agent cannot be recommended to use in occupied area because of the toxicity of carbon dioxide [16]

Recently, Lott et al. reported synergism between halon $1301\left(\mathrm{CF}_{3} \mathrm{Br}\right)$ or halon 1211 $\left(\mathrm{CF}_{2} \mathrm{ClBr}\right)$ and carbon dioxide or nitrogen [17]. Their results on the mixture of halon 1211 and carbon dioxide has also the same tendency as the results shown in FIGURE 5. It means that the multiplier effect observed in the present study is not limited to only halon 1301-containing mixtures, but it can also be expected for other halons-inert gas mixtures.

In view of practical application of this multiplier effect, to demonstrate the reduction in the amount of halon 1301 required for flame extinction, the experimental data shown in FIGURE 3 was replotted in a different manner. FIGURE 6 shows the flow rate of halon 1301 at the extinction of the cup burner flame, as a function of the inert gas mole fraction in the mixed agent. In the figure, nitrogen has larger reduction effect on halon flow rate than argon, and carbon dioxide causes the largest reduction effect. The amount of halon 1301 required for extinction decreases to $1 / 2$ or less by using the mixed agents of $10 \%$ of halon 1301 and $90 \%$ of inert gas. Such reduction may offer possibility to extend the available period of halon 1301 .

\section{Flame-extinction temperature}

The flame-extinction temperatures were calculated for the cup burner flames to consider the multiplier effect of the mixed agents of halon 1301 and inert gases. The results are shown in FIGURE 7 as a function of mole fraction of inert gas. The temperatures are constant near 1850 $\mathrm{K}$ for the flames extinguished by the carbon dioxide-argon mixed agents, and $1830 \mathrm{~K}$ by nitrogen. The flame-extinction temperatures are almost the same for all inert gases examined. Hence the constant flame-extinction temperature is considered as a typical flame-extinction temperature of cup burner flames suppressed thermally in the study. These facts also support the validity of the assumption to derive Eqn. 1 for the flame extinction by inert gases.

In contrast, the mixed agents containing halon 1301 extinguished the cup burner flames at higher temperature than the inert gas agents. The flame-extinction temperatures only decrease from 2200 to $2100 \mathrm{~K}$ at the inert gas mole fraction region of less than 0.9. Such high temperature clearly indicates that the mixed agents contained halon 1301 act as chemical fireextinguishing agents. From FIGURE 5 and FIGURE 7, it is concluded that (1) the chemical 


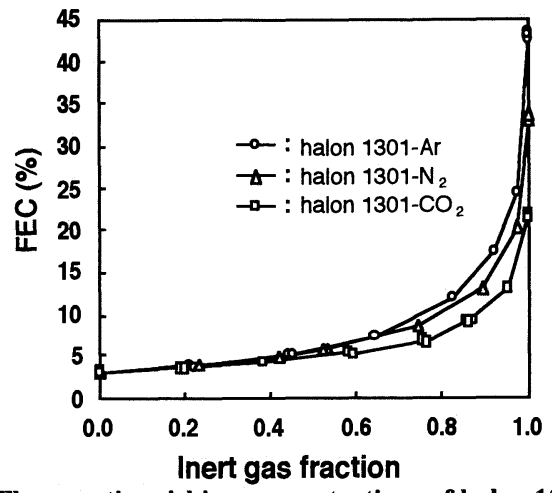

FIGURE 3 Flame-extinguishing concentrations of halon 1301-inert gas mixtures for $n$-heptane flame as functions of inert gas mole fraction

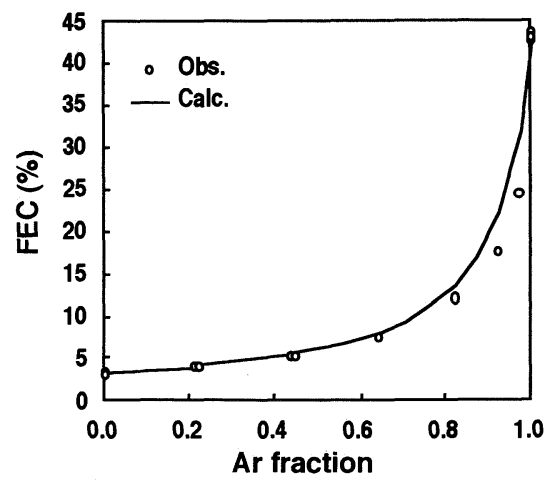

FIGURE 4 Comparison between observed and calculated flame-extinguishing concentrations of halon 1301-Ar mixture as a function of $\mathrm{Ar}$ mole fraction

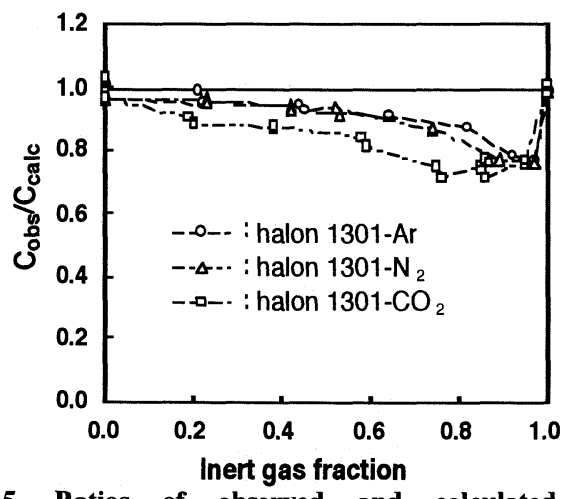

FIGURE 5 Ratios of observed and calculated flame-extinguishing concentrations of halon 1301-inert gas mixtures for $n$-heptane flame as functions of inert gas mole fraction 


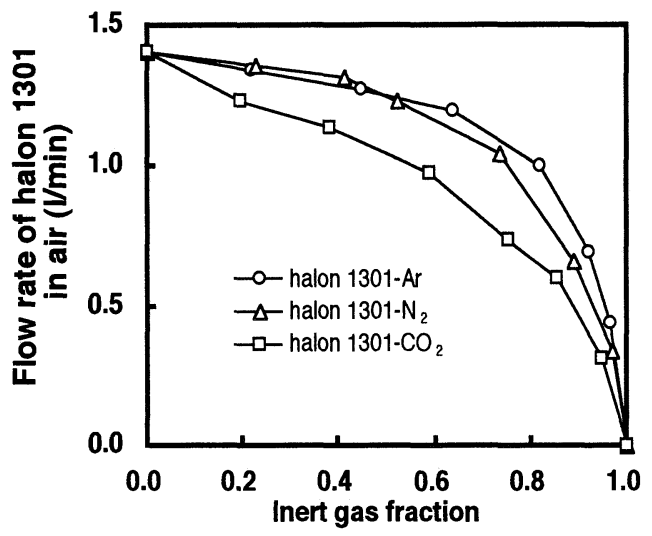

FIGURE 6 Required flow rates of halon 1301 for flame extinction by mixed agents in air flow of cup burner appatus as functions of inert gas fraction

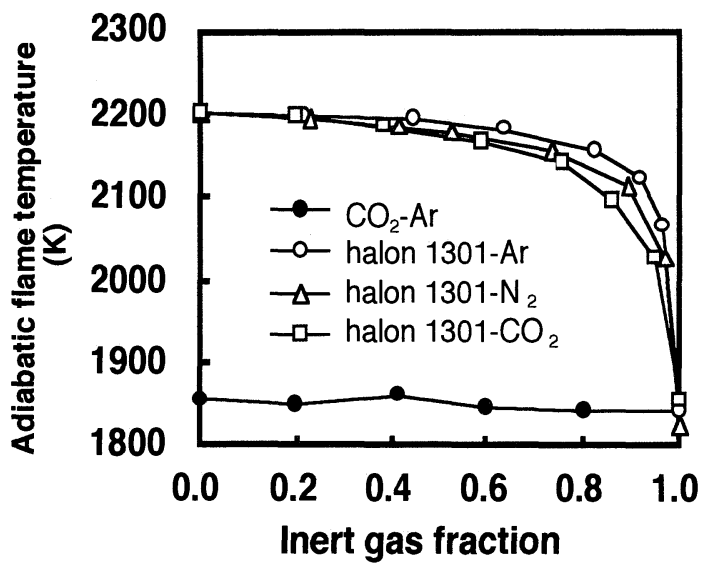

FIGURE 7 Variation of Adiabatic temperatures of n-heptane flame at the extinction by mixed agents with inert gas fraction 
flame-suppression effect is enhanced even by the slight decrease of temperature less than 100 $\mathrm{K}$, (2) the effect becomes smaller in the regain of more than 0.95 of the inert gas fraction, and (3) carbon dioxide is the most effective, probably because of its largest specific heat in the inert gases.

FIGURE 8 shows the difference between flame-extinction temperatures calculated for the cup burner flames with the observed and the estimated flame-extinguishing concentrations of the mixed agents. The symbol of $\left(\mathrm{T}_{\mathrm{f}}, \mathrm{ad}\right)_{\mathrm{O}}$ denotes the adiabatic temperatures of $\mathrm{n}$-heptane flame containing the observed flame-extinguishing concentration of the agents, and the temperature $\left(\mathrm{T}_{\mathrm{f}, \mathrm{ad}}\right)_{\mathrm{c}}$ obtained for the flame with the concentration of agents calculated by Eqn.1. So, the differences reflect degree of the chemical effect of the mixed agents.

In the case of carbon dioxide-argon mixed agents, all the temperature differences are nearly equal to zero because the agent does not show chemical effect. On the other hand, the mixed agents of halon 1301 and inert gases increase the flame temperature differences exponentially with increasing inert gas fraction. The difference reaches maximum at high inert gas fraction of about 0.95 , and then it abruptly decreases to zero with further increment of the mole fraction of inert gas. The facts clearly suggest the existence of the multiplier effect of halon 1301 and inert gases. The above variation of the temperature difference, or multiplier effect, can be explained by the competition between the higher suppression effect caused by the flame temperature decrease, and the lower suppression effect caused by decrease in halon concentration with increasing inert gas mole fraction of the mixed agents.

Further investigation is necessary to give conclusive explanations in detail for the multiplier effect observed in the present study, such as numerical simulation with detailed chemistry. Interaction between fluorinated hydrocarbons, used as halon replacements, and inert gases is another subject to be examined. In view of the fact that the inhibition chemistry is recognized to be significantly different between fluorinated hydrocarbons and halon 1301 [18], the fluorinated hydrocarbon mixtures are supposed to show different effects of interaction from that observed on halon 1301 mixtures.

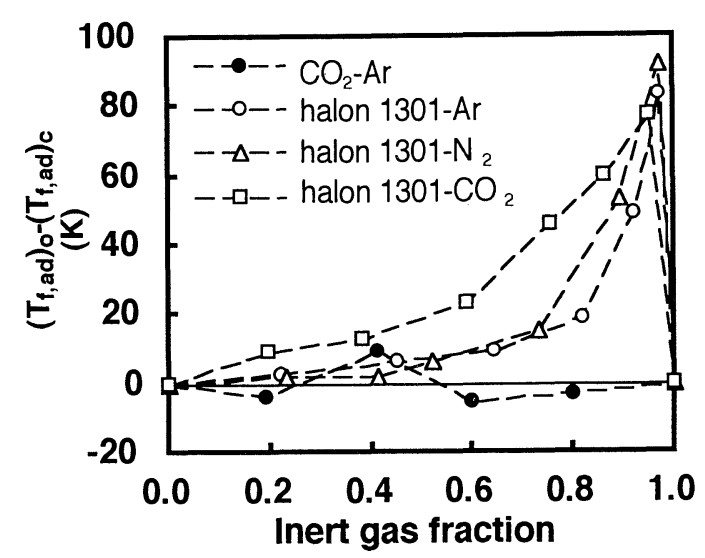

FIGURE 8 Fame temperature difference between (Tf,ad)o and (Tf,ad)c as functions of inert gas mole fraction

(Tf,ad)o and (Tf,ad)c are the adiabatic flame temperatures at flame-extinction conditions with observed and calculated concentrations of mixed agents in air, respectively. 


\section{CONCLUSION}

The fire-extinguishing effect of mixed agents of halon 1301 and inert gases has been studied by the flame-extinguishing concentration of the FRI cup burner for $n$-heptane flame.

A simple equation of the fire suppression efficiency was discussed and proposed for non interactive mixed agents. The equation was tested by comparison with the experimental data on carbon dioxide-argon or nitrogen mixed agents, and it is concluded that the equation can be used as the additive-property expression on the flame-extinguishing efficiency of mixed agents. The flame-extinguishing concentrations have been measured for the mixed agents of halon 1301 and argon, nitrogen, or carbon dioxide and compared with the calculated flame-extinguishing concentrations by the proposed equation. As a result, the multiplier effects of the mixed agents on the fire suppression efficiency were found. There are the optimized mixing ratios of halon 1301 and the inert gases.

The flame-extinction temperature of the cup burner flame has been calculated at the observed flame-extinguishing concentrations of the mixed agents. The calculated flame temperatures indicated that the inert gases caused decrease in flame temperature, and then the chemical flame inhibition effect was enhanced by the flame temperature decrease. This means the multiplier effect of the halon 1301-inert gas mixed agents on fire suppression efficiency.

\section{REFERENCES}

1. United Nation Environmental Program (UNEP), "Montreal Protocol on Substances that Deplete the Ozone Layer" Report of the Halon Fire-extinguishing Agents Technical Options Committee, 1994

2. Fire Research Institute, "1993 Annual Report of Committee for Evaluation on Toxicity of Halon Replacements", 1994 (in Japanese)

3. US National Fire Protection Association, "NFPA2001 Standard on Clean Agent Fireextinguishing Systems", 1996

4. Fristrom, R.M., "Combustion Suppression (A Literature Survey with Commentary)", Fire Research Abstracts and Reviews, 9, pp. 125-152, 1967

5. Breen, D.E., "Interactions in Binary Halon Mixtures Used as Fire Suppressants", Fire Technology, 13, 261- , 1977

6. Fristrom, R.M. and van Tiggelen, P., "An Interpretation of the Inhibition of C-H-O Flames by C-H-X Compounds", in Seventeenth Symposium (international) on Combustion, pp. 773-785, The Combustion Institute, 1978

7. Westbrook, C.K., "Numerical Modeling of flame Inhibition by CF3Br", Comb. Sci. Tech., 34, 201-225, 1983

8. Otsu, Y., Saito, N., Saso, Y., Ogawa, Y., and Sakei, Y., "Measurement of Flame Extinguishing Concentrations for Recycle Halon 1301", Annual Conference of Japanese Fire Safety Association in 1995, pp. 56-59, Kobe, JAFSS Paper A-16, 1995

9. Saito, N., Ogawa, Y., Saso, Y., Liao, C., and Sakei, R., "Flame-extinguishing Concentrations and Peak Concentrations of $\mathrm{N}_{2}, \mathrm{Ar}, \mathrm{CO}_{2}$, and Their Mixtures for Hydrocarbon Fuels", Fire Safety J., 27: , 1996 (in print)

10. Kikui, H., Saito, N., Ogawa, Y., Sakei, R., and Otsu, Y., "Improvement of Fire Extinguishing Efficiency by Halon 1301 and Inert Gases", Annual Conference of 
Japanese Fire Safety Association in 1996, pp. 56-59, Tokyo, JAFSS Paper A-16, 1996

11. Coward, H. F. and Jones, G. W., "Limits of Flammability of Gases and Vapors", Bureau of Mines Bull. 503, 1952

12. Saito, N., Saso, Y., Ogawa, Y., Inoue, Y., Sakei, R., and Otsu, Y., "Improvement on Reproducibility of Flame-extinguishing Concentration Measured by Cup Burner Method", Halon Options Technical Working Conference, pp. 299-309, Albuquerque, 1995

13. Williams, F.A., Combustion Theory, 2nd ed., The Benjamin/Cummings Publishing, Tokyo, 1985

14. Gordon, S. and McBride, B.J., "Computer Program for Calculation of Complex Chemical Equilibrium Compositions, Rocket Performance, Incident and Reflected Shocks, and Chapman-Jouguet Detonations", NASA SP-273, NASA, 1971

15. Sakei, R., Saito, N., Saso, Y., Ogawa, Y., and Inoue, Y., "Flame-extinguishing Concentrations of Halon Replacements for Flammable Liquids", Report of Fire Research Institute of Japan, No. 80, 36-42, 1995 (in Japanese)

16. Hommel, G., Handbuch der gefährlichen Güter, Merkblatt 115, Springer-Verlag, Berlin, 1978

17. Lott, J.L., Christian, S.D., Sliepcevich, C.M., and Tucker, E.E., "Synergism Between Chemical and Physical Fire-Suppressant Agents", Fire Technology, 32:3, 260-271, 1996

18. Miziolek, A.W. and Tsang, W. (Ed.), Halon Replacements: Technology and Science, ACS Symposium Series 611, American Chemical Society, Washington, D.C., 1995. 